\title{
Cross-Cultural Differences in the Perception of Portfolio Risk
}

\author{
Lucy F. Ackert ${ }^{1, *}$, Bryan K. Church ${ }^{2}$ and Li Qi ${ }^{3}$ \\ ${ }^{I}$ Department of Economics and Finance, Michael J. Coles College of Business, Kennesaw State University, 1000 Chastain Road, \\ Kennesaw, Georgia 30144. \\ ${ }^{2}$ Scheller College of Business, Georgia Tech. Atlanta, Georgia 30308. \\ ${ }^{3}$ Department of Economics and Business Management, Agnes Scott College, 141 E. College Avenue, Decatur, Georgia 30030.
}

\begin{abstract}
This paper provides cross-cultural perspective on how people evaluate assets and, importantly, create investment portfolios. We design an experiment to systematically examine how risk attitude and perception impact the evaluation of risky assets and portfolios across distinct cultures. Our Chinese participants are less risk averse in their perceptions of individual assets, but their portfolio asset allocation decisions are consistent with lower tolerance for risk. American participants place much more money at risk, and gender differences are striking with men being significantly more risk seeking.
\end{abstract}

Keywords: Cultural differences, laboratory experiments, portfolio choice, risk preferences.

JEL: C92, G15.

\section{INTRODUCTION}

This paper reports the results of an experiment designed to examine individuals' risk attitudes and perceptions, as well as their resulting investment choices. While earlier research has examined risk perception for individual assets, our focus is on decisions regarding the allocation of assets in portfolios (e.g., Bontempo, Bottom, and Weber, 1997; Weber and Hsee, 1998). Risk assessment is an important aspect of every investment decision. In the traditional finance framework, optimal portfolios are formed by risk-averse investors who define their preferences in terms of the mean and standard deviation of expected returns. Markowitz's (1952) groundbreaking work defines the Efficient Frontier as the set of portfolios that maximizes return for each given level of risk. In modern portfolio theory an asset cannot be properly evaluated based on its own merits because some risk can be eliminated by forming portfolios. The purpose of this research is to provide a cross-cultural perspective on how people evaluate assets and, in turn, create portfolios.

Giuso, Sapienza, and Zingales (2009) document the significant impact of cultural differences on economic exchange. Using the results of a survey of managers across five European countries, these authors conclude that cultural aspects impact economic outcomes, such as the level of trade, even after controlling for the characteristics of the countries. From a finance perspective, risk plays a central role in decision making. Importantly, differences in risk attitude and perception have been reported across cultures. For example, Bontempo, Bottom, and Weber (1997) and Weber and Hsee

*Address correspondence to this author at Department of Economics and Finance Michael J. Coles College of Business Kennesaw State University, 1000 Chastain Road, Kennesaw, Georgia 30144; Tel: (470) 578-6111;

E-mail: lackert@kennesaw.edu
(1998) report significantly less risk aversion among Asian research participants, as compared to the American or other Western respondents. Importantly, the source of the difference is in how risks are perceived, rather than in attitudes toward risk (Weber and Milliman, 1997). Differences in risk perception arise from differences in each culture's degree of collectivism. In a collectivist system, a cushion for negative outcomes exists (Weber and Hsee, 2000).

Differences in risk perception across cultures have implications for negotiation and exchange. The value of an asset will differ if the parties perceive the risks to be different. Previous studies have examined risk preferences and find that most people are risk averse (Holt and Laury, 2002). Further, the level of risk aversion increases with the stakes (Holt and Laury, 2002), except for low probability lotteries in which case risk seeking is reported (Kachelmeier and Shehata, 1992). This research contributes to the existing literature in that it systematically examines how risk attitude and perception impact the evaluation of risky assets and portfolios across distinct cultures.

Portfolio choice theory is a bedrock of modern finance, though the evidence suggests that people simply do not hold optimal portfolios. Empirical analyses of individual portfolio holdings suggest they are not diversified (e.g., Blume and Friend, 1975; Benartzi and Thaler, 2001).

Furthermore, the results of experimental asset markets typically indicate allocational inefficiencies (e.g., Copeland and Friedman, 1991; Ackert and Church, 1998). A recent experimental study of portfolio choice provides evidence that people will hold optimal portfolios, but only under certain, very specific conditions. Ackert, Church, and Qi (2016) report that if the variance cost of an imbalanced portfolio is large and when the potential impact of cognitive biases is mitigated, experimental participants hold optimal portfolios. Build- 
ing on Ackert, Church, and Qi (2016) we use an experimental method to investigate how observed cross-sectional differences in risk perception impact portfolio choices.

Though not without some impediments to trade, financial markets are increasingly integrated on the global stage. Researchers have reported cross-cultural differences in preferences, but how and whether these differences shape individual asset allocation decisions has not received attention. The goal of this paper is to provide insight into these questions by systematically examining individuals' risk attitudes and perceptions across cultures, with a focus on their resulting portfolio choices.

The remainder of the paper is organized as follows. Section I provides a general framework for our experimental investigation. Section II describes the experimental procedure Section III reports the results of our analysis and the directions for further analysis. Section IV provides preliminary conclusions.

\section{FRAMEWORK}

We recruited student participants in China at Beijing Normal University and in the United States at Georgia Tech. Participants, who come from a variety of majors, were asked to complete financial decision-making tasks requiring approximately one hour of time. Our research builds upon the experiments conducted by Weber and Hsee (1998) who measured cross- cultural differences in the perception of risk for individual investment options. Weber and Hsee reported that most of their experimental participants were perceived to be risk averse. Chinese participants were significantly less risk averse than their American counterparts but the source of the difference was their perception of risk, rather than their attitudes towards perceived risk.

In their design, Weber and Hsee presented experimental participants with 12 risky investment options. ${ }^{1}$ Participants were asked to evaluate each of the 12 options, individually, along two dimensions. The investment options had three possible payoffs, depending on the state of nature, and each option had at least one possible gain and one possible loss. First respondents were asked "what is the maximum amount you would be willing to pay to get a chance at this investment option? (If you wouldn't buy it at any price, say $\$ 0$.)" This is referred to as the respondent's willingness to pay (WTP). Second, they were asked "how risky do you think this investment option is?" Respondents' perceptions of risk were reported on a numerical scale ranging from 0 (not at all risky) to 100 (extremely risky).

In addition to eliciting WTP and risk perception, we ask our experimental participants to allocate an endowment of money across a portfolio of four investment options and cash. The purpose of this additional exercise is to provide insight into the relationship between risk perception and portfolio allocation decisions. In our design, we follow Ackert, Church, and Qi (2016) who examine the factors that compel people to hold optimal portfolios.

\footnotetext{
${ }^{1}$ See Weber and Hsee (1998, Table 1, page 1210).
}

Weber and Hsee paid their respondents a flat fee. In our experiment, we directly incentivize choice by tying compensation to portfolio selection. At the end of each experimental session, a lottery was actually played. A participant's monetary compensation depended on the portfolio selected as well as the outcome observed. In addition, as described subsequently, we elicited a number of measures of individual psychology in order to examine how risk attitude and perception vary across additional dimensions of personality.

\section{EXPERIMENTAL DESIGN}

\section{A. Overview and Participants}

The experiment was conducted at large, public universities in the United States and China, with 47 (50) completing the experiment in the U.S. (China). ${ }^{2}$ All participants were university students across a variety of majors. Students earned from $\$ 10$ to $\$ 55$ ( $¥ 30$ to $¥ 96$ ) for approximately one hour of time. $^{3}$

\section{B. Procedures}

At the beginning of each session participants received a set of instructions, describing three tasks: an initial survey, investment choices, and a post-experiment questionnaire. After an experimenter read the instructions aloud, the experimenter addressed any procedural or technical questions. ${ }^{4}$ Though the data of primary interest consist of participants' investment choices, we first administered a questionnaire to assess several psychologcal characteristics.

The initial survey included fourteen questions in total and participants were paid $\$ 5$ for its completion to encourage attentiveness. The first ten questions are designed to measure participant optimism. Psychologists report that optimistic people do not just feel better but they actually benefit from their optimism in terms of improved life outcomes (Scheier and Carver, 1992). Optimists take on obstacles thrown in their path and they deal better with stress, resulting in better psychological and physical health. To measure optimism we use the revised Life Orientation Test (LOT-R) developed by Carver, Scheier and Segerstrom (2010). This ten- question survey measures respondents' overall level of optimism or pessimism. We use this survey because it is short, easy to implement, and frequently used in psychology and behavioral research. Participants' responses are numerically coded so that high scores indicate optimism and low scores indicate pessimism.

The next set of questions in the survey measure personal risk aversion following Barsky, Kimball, Juster, and Shapiro (1997) as adjusted for status quo bias by Graham, Harvey,

\footnotetext{
${ }^{2}$ Both universities are highly regarded internationally with stringent, competitive entrance requirements.

${ }^{3}$ Three students ended with negative earnings and received the minimum compensation of $\$ 10$ ( $¥ 30$ ). Our procedures accord with the standards set by the university review board which would preclude taking money from student participants.

${ }^{4}$ The complete instructions (in English) are included in Appendix 1. The instructions for the sessions in Beijing were translated from the English version by a native Chinese speaker. We used the same payouts for each asset in China, converting participants' final earnings to yuan at the prevailing exchange rate at the conclusion of each session.
} 
and Puri (2013). The risk tolerance question asks participants to choose beteen a job with safe income and one with risky income. Participants who consistently choose the safe income level are categorized as the most risk averse and we refer to these participants as "extremely risk averse."

Next, the survey included a question to measure loss aversion. Behavioral scientists have documented that people are averse to losses so that the loss of money is experienced more strongly than a gain of equivalent size (Tversky and Kahneman, 1991). We asked participants to choose between two lotteries. The first has a higher expected value but a chance of loss. The second, lower expected payoff lottery involves only potential gains. Participants who choose the second lottery are categorized as loss averse.

The final question of the initial survey is designed to measure time preference. Following Loewenstein, Read, and Baumeister (2003) participants were asked to choose between money today and a larger sum in a year. We categorize those who choose the money today as impatient because the implied discount rate exceeds $30 \%$.

Participants' second task involved investment and portfolio choices. First participants made decisions for four investment options, referred to as options $\mathrm{M}, \mathrm{N}, \mathrm{O}$, and $\mathrm{P}$, all with an expected payoff value of $\$ 150$. Options $\mathrm{M}$ and $\mathrm{N}$ had equally likely payoffs of 0 and $\$ 300$, with the payoffs being perfectly negatively correlated for the two options. Similarly, options $\mathrm{O}$ and $\mathrm{P}$ had perfectly negatively correlated payoffs, but now losses were possible with payoffs of $-\$ 150$ and $\$ 450$. The four investment options, as well as their expected value and standard deviations, as summarized in Table $\mathbf{1}$. For each of the four investment options, participants were asked to respond to two questions. First, following Weber and Hsee (1998), they were asked how much they are willing to pay for the option (WTP) and, second, they are asked to rate the risk of the option on a scale of 0 to 100 where $0=$ not at all risky and $100=$ extremely risky.

Table 1 Investment Options.

\begin{tabular}{|c|c|c|c|c|}
\hline $\begin{array}{c}\text { Investment } \\
\text { Option }\end{array}$ & \multicolumn{2}{|c|}{ Possible Outcomes } & $\begin{array}{c}\text { Expected } \\
\text { Value }\end{array}$ & $\begin{array}{c}\text { Standard } \\
\text { Deviation }\end{array}$ \\
\hline M & 300 & 0 & 150 & 106.07 \\
\hline N & 0 & 300 & 150 & 106.07 \\
\hline O & 450 & -150 & 150 & 212.13 \\
\hline P & -150 & 450 & 150 & 212.13 \\
\hline Cash & \multicolumn{3}{|c|}{ Amount invested } \\
\hline
\end{tabular}

Next, participants turned to the portfolio investment task. They were given the four investment options described above and told that they had $\$ 3,000$ in experimental dollars to invest. They were also instructed that they could buy a unit of each investment option from the experimenter at $\$ 150$, but they could also hold cash. We follow Rietz (2005)

${ }^{5}$ The most risk averse participants choose the safe income so they choose (A.) for question 11 and then (A.) again for questions 12.A. and Ackert, Church, and Qi (2016) in allowing participants to buy either asset at its expected payoff. In addition, portfolio rebalancing is costless in our trading environment. Traders could eliminate all risk by holding cash or two risky assets in equal numbers $(\mathrm{M} / \mathrm{N}$ or $\mathrm{O} / \mathrm{P})$ because of the negative correlation in asset payoff among the pairs. After two practice allocations to ensure participant understanding, participants made allocations and the experimenters flipped a coin in the view of all participants to determine their earnings for this portion of the experiment.

Finally, participants completed a 20-question survey which included demographic questions as well as additional psychological measures. Again participants were paid $\$ 5$ for completion of the questionnaire to encourage attentiveness. In addition to their course of study, financial experience, age, sex, and nationality, we asked participants to report their height in feet and inches. Persico, Postlewaite, and Silverman (2004) report that taller people earn higher wages compared to those who are shorter. This disparity may arise because confidence may be promoted by height (Graham, Harvey, and Puri, 2013). The survey's final three questions measure cognitive abilty. Frederick (2005) describes the Cognitive Reflection Test (CRT), an intelligence measure that has practical benefits because it is a very short survey and responses are easy to evaluate. While the measure is certainly not a perfect gauge of cognitive ability, CRT scores have been shown to be useful in understanding decisionmaking (Frederick, 2005). People with higher cognitive ability tend to be less risk averse and more patient (e.g., Dohmen, Falk, Huffman, and Sunde, 2010; Ackert, Deaves, Miele, Nguyen, 2018). The three simple questions that comprise the CRT have correct numerical answers. Because some incorrect answers seem intuitive, a high score indicates that the respondent used cognitive reflection to arrive at the correct response. A participant's cognitive score is easily computed as the number of correct responses, 0 through 3 .

\section{RESULTS}

Table 2 details the observed characteristics of our participants in the United States and China. Though the percentage of American participants who are men $(52 \%)$ exceeds the precentage in China (44\%), the difference is not statistically significant. We also find no significant differences in average age, optimism, extreme risk aversion, or impatience across partiipants in the United States and China. Our participants are more often business and economics majors in the U.S. We observe that the American participants are, on average, significantly taller and more confident in their financial expertise than the Chinese participants. The summary information also suggests that the Americans are significantly more loss averse, while the Chinese score higher in cognitive ability. Looking simply at sample means, the difference in extreme risk aversion is not statistically significant across American and Chinese participants. The figure for the American participants of $11 \%$ is in line with the average of $9.8 \%$ reported by Graham, Harvey, and Puri (2013) for U.S. CEOs.

Table 3 summarizes participants' willingness to pay for each asset, as well as their subjective risk assessments. Based on the literature, our hypothesis is that the Chinese participants 
are less risk averse so the table reports significance levels for one-tailed tests. For each of the four investment options, the average willingness to pay (WTP) does not differ significantly across the two countries, though the WTP is higher for the Chinese participants which is consistent with lower risk aversion. Recall that each asset has an expected value of 150 , so averages less than 150 are consistent with risk aversion. Recall also that participants were permitted to report a WTP of 0 if they did not wish to buy at any price. No subject reported WTP of zero for assets M and N, though four Chinese and 5 American subjects were in this category for assets $\mathrm{O}$ and $\mathrm{P}$. This suggests substantial loss aversion as assets $\mathrm{O}$ and $\mathrm{P}$ had possible negative payouts. In regard to their perceptions of risk, the results indicate that there are considerable differences across Western and Asian respondents, with the Chinese indicating lower risk perception. This is consistent with the differences in risk perception reported in the extant literature across Western and Asian people (Weber and Millimam, 1997; Weber and Hsee, 1998). The average perceived risk is higher for all four investment options for American participants, and significantly higher for three of four.

Table 2. Subject Characteristics

\begin{tabular}{|c|c|c|}
\hline & U.S. & China \\
\hline Total number of subjects & 47 & 50 \\
\hline Men (percentage) & $52 \%$ & $44 \%$ \\
\hline Age (mean) & 21 & 23 \\
\hline Business or Economics major (percentage) $* * *$ & $\mathbf{9 3 \%}$ & $\mathbf{3 6 \%}$ \\
\hline Height (mean in inches) $* *$ & $\mathbf{6 7 . 5 0}$ & $\mathbf{6 5 . 8 6}$ \\
\hline Characterization of financial expertise (mean) $*$ & $\mathbf{6 . 1 6}$ & $\mathbf{5 . 4 4}$ \\
\hline Optimism (mean) & 17.24 & 16.12 \\
\hline Extreme risk aversion (percentage) & $11 \%$ & $6 \%$ \\
\hline Loss aversion (percentage) $* *$ & $\mathbf{6 5 \%}$ & $\mathbf{4 4 \%}$ \\
\hline Impatience (percentage) & $37 \%$ & $40 \%$ \\
\hline Cognitive score (mean) $* * *$ & $\mathbf{1 . 7 2}$ & $\mathbf{2 . 7 6}$ \\
\hline
\end{tabular}

Notes: Entries in bold are statistically different. $* * *, * *, *$ denotes significance at the $1 \%, 5 \%$, and $10 \%$ level, respectively, two-tailed test.

Our goal in designing the experiment was to provide insight into portfolio decisions.

Table 4 presents average investments in each of the four risky assets and cash across subjects in the two countries. We observe no significant differences for any single asset. However, we do see a substantial difference in how much money participants are willing to put at risk. Recall that assets $\mathrm{M}$ and $\mathrm{N}$, as well as $\mathrm{O}$ and $\mathrm{P}$, have perfectly negatively correlated payoffs. Thus, the difference between investments in $\mathrm{M}$ and $\mathrm{N}$, as well as $\mathrm{O}$ and $\mathrm{P}$, is unhedged money at risk. We compute the percentage of Money at risk as

$$
\text { Money at risk }=(|\mathrm{M}-\mathrm{N}|+|\mathrm{O}-\mathrm{P}|) / 3,000
$$

where 3,000 is the endowment received by each participant. The last row of Table 4 reports the average for each participant group and we see that the Americans have significantly more money at risk than the Chinese. This is perhaps surprising as the Americans report being significantly more loss averse and, though not significant, the Americans are also slightly more averse to extreme risk (see Table $\mathbf{2}$ ).

\section{Table 4. Portfolio Investment Decisions.}

The table reports the average investment across subjects for each country and investment option. The Money at risk is computed as $(|\mathrm{M}-\mathrm{N}|+|\mathrm{O}-\mathrm{P}|) / 3,000$.

\begin{tabular}{|c|c|c|c|}
\hline \multirow{2}{*}{} & \multicolumn{2}{|c|}{ Investment } & \multirow{2}{*}{ t-statistic } \\
\cline { 2 - 3 } & American & Chinese & \\
\hline $\mathrm{M}$ & 0.14 & 0.18 & -1.15 \\
\hline $\mathrm{O}$ & 0.15 & 0.13 & 0.72 \\
\hline $\mathrm{P}$ & 0.27 & 0.25 & 0.81 \\
\hline Cash & 0.15 & 0.15 & 0.01 \\
\hline Money at risk & 0.28 & 0.31 & -0.44 \\
\hline
\end{tabular}

Notes: Entries in bold are statistically different. $* * *, * *, *$ denotes significance at the $1 \%, 5 \%$, and $10 \%$ level, respectively, two-tailed test.

We look deeper into the data to better understand participant behavior. We find that 10 participants were extreme risk takers and invested all of their endowment $(3,000)$ in either asset $\mathrm{O}$ or asset $\mathrm{P}$. Of these 10, seven are American and three are Chinese. At the other extreme, some participants took no risk at all. Of the 46 Americans, 20 (43\%) fall in this group and, of the 50 Chinese, 18 (36\%) put no money at risk. So, while many participants take no risk, consistent with risk aversion and risk neutral pricing, a substantial group (10\%), particularly of Americans (15\%), takes the maximum possible risk. The fact that all of the 10 risk takers are male is noteworthy.

Table 3. Judgments of WTP and Risk.

The table reports the average willingness to pay and subjective measure of risk (on a scale of 0 to 100) for subjects in each country for each investment option.

\begin{tabular}{|c|c|c|c|c|c|c|}
\hline \multirow{2}{*}{$\begin{array}{c}\text { Investment } \\
\text { Option }\end{array}$} & \multicolumn{2}{|c|}{ WTP } & \multirow{2}{*}{ t-statistic } & \multicolumn{3}{|c|}{ Risk } \\
\cline { 2 - 5 } & American & Chinese & & American & Chinese \\
\hline M & 105.57 & 117.54 & -0.92 & 45.91 & 37.80 & $1.94 * *$ \\
\hline N & 110.35 & 117.54 & -0.54 & 45.20 & 37.70 & $1.74 * *$ \\
\hline O & 108.28 & 117.42 & -0.49 & 65.89 & 59.96 & 1.24 \\
\hline P & 111.98 & 116.94 & -0.25 & 67.65 & 60.36 & $1.53 *$ \\
\hline
\end{tabular}

Notes: Entries in bold are statistically different. $* * *, * * *$ denotes significance at the $1 \%, 5 \%$, and $10 \%$ level, respectively, one-tailed test. 
We conduct additional analysis to delve into the summary findings and better understand participant behavior. Table $\mathbf{5}$ reports the results of a regression in which the dependent variable is Money at risk. The independent variables include Gender $(1=$ Male), Height (in inches), Financial expertise (self-evaluation on scale of 0 to 11), Optimism, Extreme risk aversion, Loss Aversion, Impatience, Cognitive score, and Country $(1=$ China $)$. The results indicate that Gender, Height, Extreme risk aversion, and Country have significant effects on the amount of money participants risk in our portfolio allocation task.

Table 5. Regression of Factors Affecting Participants' Money at Risk

The table reports the results of an OLS regression in which the dependent variable is Money at risk, computed as $(|\mathbf{M}-\mathbf{N}|+\mid \mathbf{O}$ - P|) / 3,000. The sample includes the portfolio choices of 96 participants. The independent variables include Gender $(1=$ Male), Height (in inches), Financial expertise (self-evaluation on scale of 0 to 11), Optimism, Extreme risk aversion, Loss aversion, Impatience, Cognitive score, and Country ( $1=$ China). For the overall regression, $F=4.34(p<0.001)$, and adjusted $R^{2}=$ 0.36 .

\begin{tabular}{|c|c|}
\hline Independent variable & Estimated Coefficient (t-statistic) \\
\hline Constant & $\begin{array}{c}1.5639 \\
(2.09)^{* * *}\end{array}$ \\
\hline Gender & $\begin{array}{c}0.3370 \\
(4.29)^{* * * *}\end{array}$ \\
\hline Height & $\begin{array}{l}-0.0187 \\
(-1.84)^{*}\end{array}$ \\
\hline Financial expertise & $\begin{array}{l}0.0011 \\
(0.08)\end{array}$ \\
\hline Optimism & $\begin{array}{l}0.0098 \\
(1.54)\end{array}$ \\
\hline Extreme risk aversion & $\begin{array}{c}-0.1981 \\
(-2.66)^{* * * *}\end{array}$ \\
\hline Loss aversion & $\begin{array}{c}-0.0812 \\
(-1.14)\end{array}$ \\
\hline Impatience & $\begin{array}{l}0.0246 \\
(0.39)\end{array}$ \\
\hline Cognitive score & $\begin{array}{l}0.0494 \\
(1.61)\end{array}$ \\
\hline Country & $\begin{array}{c}-0.2133 \\
(-2.99)^{* * *}\end{array}$ \\
\hline
\end{tabular}

Notes: Entries in bold are statistically different. $* * *, * *, *$ denotes significance at the $1 \%, 5 \%$, and $10 \%$ level, respectively, two-tailed test.

A large and growing literature reports on the importance of sex when it comes to people's preferences. In general, women are more risk averse than men (Barksy et al., 1997; Fred- erick, 2005; Dohmen, et al. 2011). ${ }^{6}$ Consistent with this observation, men in our sample are more willing to hold an imbalanced portfolio and keep some cash at risk. We also find that taller people are less willing to hold funds at risk. Graham, Harvey, and Puri, (2013) report that firms with higher growth tend to be run by executives who are more risk tolerant and taller, positing that height may be correlated with confidence. In our portolfio task, taller participants are not prone to put more of their assets at risk. Not surprisingly, participants who are extremely risk averse as measured by the Graham, Harvey, and Puri, (2013) method are significantly less likely to put money at risk. Finally, participants' home country has a highly significant impact on portfolio formation. Americans are much more likely to hold risky assets in an imbalanced portfolio.

\section{SUMMARY AND CONCLUDING REMARKS}

We report the results of an experiment designed to investigate how individual psychology impacts investment decisions. While we recognize that there are limitations to the generalizability of our study, we believe that our simple experimental environment provides insight into behavior in naturally-occurring settings. We are able to measure and isolate the effects of various factors on participants' choices. Of course, our measures are not perfect proxies for psychological factors and may not fully capture the behavior of interest. We believe that the benefits outweigh the costs because we are able to examine questions in a controlled environment, an exercise that cannot be accomplished in the field.

In this paper we examine individuals' risk attitudes and perceptions, but unlike earlier studies our focus is on portfolio choices. First, we find that our Chinese participants are significantly less risk averse in their perceptions of the risks of individual assets than their American counterparts, consistent with the differences in risk perception reported in the extant literature across Asian and Western people (Weber and Millimam, 1997; Weber and Hsee, 1998). Strikingly, the asset allocation decisions of Chinese participants are consistent with lower risk tolerance. The American participants place much more money at risk, suggesting greater risk seeking behavior. Importantly, we observe that level of risk tolerance changes across the decision frame, from the evaluation of individual risky assets to risky portfolios.

Zhou and Hey (2018) argue that the context is critical when it comes to eliciting risk tolerance. People do not have stable preferences when making decisions under risk, so how a task is framed plays a key role in the appropriate measure of a person's level of aversion to risk. From their comparison of techniques proposed to measure risk aversion, the take away is clear. Zhou and Hey conclude that the most appropriate measure of risk aversion is from a context that is similar to that of the target decision environment. Thus, as most investment decisions are made in a portfolio context we question the conclusion that people from collectivist cultures can generally be viewed as more risk tolerant, as compared to

\footnotetext{
${ }^{6}$ The regression analysis includes 96 observations. One American subject is excluded due to incomplete responses.
} 
Westerners. In a portfolio context, our Western participants make decisions that are consistent with greater risk tolerance.

Our evidence indicates that the portfolio decisions of Western and Asian participants are quite different, particularly at the extremes. Henrich, Heine, and Norenzayan (2010) document the frequent outliers observed in studies of WEIRD people, i.e., those from Western, Educated, Industrialized, Rich, and Democratic societies. Consistent with their findings, our American participants sometimes make choices that are clear outliers as they deviate significantly from the majority. Though we also have three Chinese participants who take an extreme amount of risk in their portfolio choice, seven of our American participants take the riskiest gamble. All of these participants are men. Yet, we have many other participants who take no risk at all. Our results highlight how the diversity in preferences may limit our ability to formulate a parsimonious model of portfolio choice.

\section{CONFLICT OF INTEREST STATEMENT}

The authors declare that they have no conflict of interest.

\section{REFERENCES}

Ackert, Lucy F., and Bryan K. Church. 1998. Information dissemination and the distribution of wealth: Evidence from experimental asset markets. Journal of Economic Behavior and Organization 37(3), 357371 .

Ackert, Lucy F., Bryan K. Church, and Li Qi. 2016. An experimental examination of portfolio choice. Review of Finance 20(4), 1427-1447.

Ackert, Lucy F., Richard Deaves, Jennifer Miele, and Quang Nguyen, 2018 Are time preference and risk preference associated with cognitive intelligence and emotional intelligence?, Working paper.

Barsky, Robert B., F. Thomas Juster, Miles S. Kimball, and Matthew D. Shapiro. 1997.

Preference parameters and behavioral heterogeneity: An experimental approach in the health and retirement study. The Quarterly Journal of Economics, 112(2), 537-579.

Benartzi, Shlomo, and Richard H. Thaler. 2001. Naïve diversification strategies in defined contribution saving plans. American Economic Review 91(1), 79-98.

Blume, Marshall E., and Irwin Friend. 1975. The asset structure of individual portfolios and some implications for utility functions, Journal of Finance 30(2), 585-603.

Bontempo, Robert N., William P. Bottom, and Elke U. Weber. 1997. Crosscultural differences in risk perception: A model-based approach. Risk Analysis 17(4), 479-488.

Carver, Charles S., Michael F. Scheier, and Suzanne C. Segerstrom. 2010. Optimism. Clinical Psychology Review 30(7), 879-89.

Copeland, Thomas E., and Daniel Friedman. 1991. Partial revelation of information in experimental asset markets. Journal of Finance 46(1), 265-295.
Dohmen, Thomas, Armin Falk, David Huffman, and Uwe Sunde. 2010. Are risk aversion and impatience related to cognitive ability?, American Economic Review 100(3), 1238-60.

Dohmen, Thomas, Armin Falk, David Huffman, Uwe Sunde, Jurgen Schupp, and Gert G. Wagner. 2011. Individual risk attitudes: Measurement, determinants, and behavioral consequences, Journal of the European Economic Association 9(3), 522-550.

Frederick, Shane. 2005, Cognitive reflection and decision making. Journal of Economic Perspectives 19(4), 25-42.

Giuso, Luigi, Paolo Sapienza, and Luigi Zingales. 2009. Cultural biases in economic exchange. The Quarterly Journal of Economics 128(3), 1095-1131.

Graham, John R., Campbell R. Harvey, and Manju Puri. 2013. Managerial attitudes and corporate actions. Journal of Financial Economics 109(1), 103-121.

Henrich, Joseph, Steven J. Heine, and Ara Norenzayan. 2010. The weirdest people in the world? Behavioral and Brain Sciences 33(2-3), 61135.

Holt, Charles A., and Susan K. Laury. 2002. Risk aversion and incentive effects. American Economic Review 92(5), 1644-1655.

Kachelmeier, Steven J., and Mohamed Shehata. 1992. Examining risk preferences under high monetary incentives: Experimental evidence from the People's Republic of China. American Economic Review 82(5), 1120-1141.

Loewenstein,Geroge, Daniel Read, and Roy Baumeister, editors. 2003. Time and Decision: Economic and Psychological Perspectives on Intertemporal Choice. Russell Sage Foundation, New York.

Markowitz, Harry. 1952. Portfolio selection. Journal of Finance 7(1), 7791.

Persico, Nicola, Andrew Postlewaite, and Dan Silverman. 2004. The effect of adolescent experience on labor market outcomes: The case of height. Journal of Politcal Economy 112(5), 1019-1053.

Rietz, Thomas A. (2005) Behavioral mis-pricing and arbitrage in experimental asset markets, Working paper, University of Iowa.

Scheier, Michael F., and Charles S. Carver. 1992. Effects of optimism on psychological and physical well-being: Theoretical overview and empirical update. Cognitive Theory and Research 16(2), 201-228.

Tversky, Amos, and Daniel Kahneman. 1991. Loss aversion in riskless choice: A reference- dependent model. The Quarterly Journal of Economics 106(4), 1039-1061.

Weber, Elke U., and Christopher Hsee. 1998. Cross-cultural differences in risk perception, but cross-cultural similarities in attitudes towards perceived risk. Management Science 44(9), 1205-1217.

Weber, Elke U., and Christopher Hsee. 2000. Culture and individual judgment and decision making. Applied Psychology: An International Review 49(1), 32-61

Weber, Elke U., and Richard A. Milliman. 1997. Perceived risk attitudes: Relating risk perception to risky choice. Management Science 43(2), 123-144.

Zhou, Wenting, and John Hey. 2018. Context matters. Experimental Economics 21(4), 723-756.

\section{APPENDIX 1 EXPERIMENTAL INSTRUCTIONS}

\section{INSTRUCTIONS}

This experiment will include 3 activities. We will begin with a survey, then we will turn to an investment task, and lastly, we will ask you to complete a post-experiment questionnaire. Each of the activities is a completely separate task and you will be paid at the conclusion of today's session for each. Your compensation for each activity is not dependent on any other task. 
Please do not confer with other participants at any time.

[New page] Survey

Please indicate your response by circling the letter of your choice for each question. Your answers are important for our research and you will be paid $\$ 5$ today for completion of the survey. Please circle the letter that corresponds to your answer.

1. In uncertain times, I usually expect the best.
A. I agree a lot.
B. I agree a little.
C. I neither agree nor disagree.
D. I disagree a little.
E. I disagree a lot.

2. It is easy for me to relax.
A. I agree a lot.
B. I agree a little.
C. I neither agree nor disagree.
D. I disagree a little.
E. I disagree a lot.

3. If something can go wrong for me, it will.
A. I agree a lot.
B. I agree a little.
C. I neither agree nor disagree.
D. I disagree a little.
E. I disagree a lot.

4. I'm always optimistic about my future.
A. I agree a lot.
B. I agree a little.
C. I neither agree nor disagree.
D. I disagree a little.
E. I disagree a lot.

5. I enjoy my friends a lot.
A. I agree a lot.
B. I agree a little.
C. I neither agree nor disagree.
D. I disagree a little.
E. I disagree a lot.

6. It is important for me to keep busy.
A. I agree a lot.
B. I agree a little.
C. I neither agree nor disagree.
D. I disagree a little.
E. I disagree a lot.

7. I hardly ever expect things to go my way.
A. I agree a lot. 
B. I agree a little.

C. I neither agree nor disagree.

D. I disagree a little.

E. I disagree a lot.

8. I don't get upset too easily.
A. I agree a lot.
B. I agree a little.
C. I neither agree nor disagree.
D. I disagree a little.
E. I disagree a lot.

9. I rarely count on good things happening to me.

A. I agree a lot.

B. I agree a little.

C. I neither agree nor disagree.

D. I disagree a little.

E. I disagree a lot.

10. Overall, I expect more good things to happen to me than bad.
A. I agree a lot.
B. I agree a little.
C. I neither agree nor disagree.
D. I disagree a little.
E. I disagree a lot.

11. Suppose you are the only income earner in your family. Your doctor recommends you move because of allergies. You have to choose between two possible jobs. Please choose one:

A. $100 \%$ chance that the job pays your current income for life.

B. $50 \%$ chance that the job pays twice your current income for life and $50 \%$ chance that the job pays $2 / 3$ of your current income for life.

Note for next two questions: You will only answer one of the following two questions. That is, you will answer 12.A or 12.B, but not both. The specific question that you will answer is determined by your answer to question 11 (the preceding question).

Please answer question 12.A ONLY if you answered A to question 11.

12. A Which job would you choose if the choices were instead:

A. $100 \%$ chance that the job pays your current income for life.

B. $50 \%$ chance that the job pays twice your current income for life and $50 \%$ chance that the job pays $4 / 5$ of your current income for life.

Please answer question 12.B ONLY if you answered B to question 11.

12. B Which job would you choose if the choices were instead:

A. $100 \%$ chance that the job pays your current income for life.

B. $50 \%$ chance that the job pays twice your current income for life and $50 \%$ chance that the job pays $1 / 2$ of your current income for life.

13. You are offered two possible lotteries. Which would you rather have? Please choose one:

A. A $50 \%$ chance of winning $\$ 50$ and a $50 \%$ chance of losing $\$ 20$

B. A $50 \%$ chance of winning $\$ 20$ and a $50 \%$ chance of winning $\$ 5$

14. Would you rather win $\$ 10,000$ now or $\$ 13,000$ a year from now? Please choose one:

A. I prefer $\$ 10,000$ now. 
B. I prefer $\$ 13,000$ in one year.

[New page] Instructions for Investment Task

We are about to begin an investment task, where you will make decisions that involve four investment options (assets $\mathrm{M}, \mathrm{N}, \mathrm{O}$, and $\mathrm{P})$.

Please follow along as the experimenter reads these instructions aloud. Feel free to ask questions at any time.

First you will be given information on each investment option. Each option has two equally-likely outcomes (in dollars).

You should assume that you are investing your own money and currently have $\$ 3,000$ available to makes investments.

On the following pages you will be asked to evaluate each of the four investment options.

[New Page] Investment Option M

The payoffs for Investment Option $\mathrm{M}$ are summarized below:

\begin{tabular}{|c|c|c|}
\hline Investment Option & Outcome 1 & Outcome 2 \\
\hline M & 300 & 0 \\
\hline
\end{tabular}

Each outcome is equally likely with a fixed probability of $50 \%$.

What is the maximum amount you would be willing to pay to get a chance at this investment option? (If you would not buy at any price, say $\$ 0$.)

I would pay \$ for a chance at this investment option.

How risky do you think this investment option is? Please express how risky this option is on a scale from $0=$ not at all risky to $100=$ extremely risky.

The risk of this asset is on a scale from 0 to 100 .

[New page] Investment Option N

The payoffs for Investment Option $\mathrm{N}$ are summarized below:

\begin{tabular}{|c|c|c|}
\hline Investment Option & Outcome 1 & Outcome 2 \\
\hline $\mathrm{N}$ & 0 & 300 \\
\hline
\end{tabular}

Each outcome is equally likely with a fixed probability of $50 \%$.

What is the maximum amount you would be willing to pay to get a chance at this investment option? (If you would not buy at any price, say $\$ 0$.)

I would pay \$__for a chance at this investment option.

How risky do you think this investment option is? Please express how risky this option is on a scale from $0=$ not at all risky to $100=$ extremely risky.

The risk of this asset is __on a scale from 0 to 100.

[New Page] Investment Option O

The payoffs for Investment Option $\mathrm{O}$ are summarized below:

\begin{tabular}{|c|c|c|}
\hline Investment Option & Outcome 1 & Outcome 2 \\
\hline $\mathrm{O}$ & 450 & -150 \\
\hline
\end{tabular}

Each outcome is equally likely with a fixed probability of 50\%.

What is the maximum amount you would be willing to pay to get a chance at this investment option? (If you would not buy at any price, say $\$ 0$.)

I would pay \$__ for a chance at this investment option.

How risky do you think this investment option is? Please express how risky this option is on a scale from $0=$ not at all risky to $100=$ extremely risky. 
The risk of this asset is on a scale from 0 to 100 .

[New Page] Investment Option P

The payoffs for Investment Option P are summarized below:

\begin{tabular}{|c|c|c|}
\hline Investment Option & Outcome 1 & Outcome 2 \\
\hline $\mathrm{P}$ & -150 & 450 \\
\hline
\end{tabular}

Each outcome is equally likely with a fixed probability of $50 \%$.

What is the maximum amount you would be willing to pay to get a chance at this investment option? (If you would not buy at any price, say $\$ 0$.)

I would pay \$__ for a chance at this investment option.

How risky do you think this investment option is? Please express how risky this option is on a scale from $0=$ not at all risky to $100=$ extremely risky.

The risk of this asset is ___ on a scale from 0 to 100.

[New Page] Portfolio Investment Task

The payoffs for each of the four investment options are summarized in the following table:

\begin{tabular}{|c|c|c|}
\hline Investment Option & Outcome 1 & Outcome 2 \\
\hline $\mathrm{M}$ & 300 & 300 \\
\hline $\mathrm{N}$ & 0 & -150 \\
\hline $\mathrm{O}$ & 450 & 450 \\
\hline $\mathrm{P}$ & -150 & 4 \\
\hline
\end{tabular}

Remember that each outcome is equally likely with a fixed probability of $50 \%$.

We are giving you $\$ 3,000$ in experimental dollars to invest. Each investment option has a fixed price of $\$ 150$ per unit. So, you have to pay $\$ 150$ for each unit of investment. Your ability to invest is only constrained by your endowment of $\$ 3,000$ : that is, you can spend up to $\$ 3,000$ investing. How much would you invest in each investment option?

The payoff factors for each of the four investment options are summarized in the table below. The payoff factor represents a multiplier, which is applied to your investment to determine your earnings.

\begin{tabular}{|c|c|c|}
\hline Investment Option & Outcome 1 & 0 \\
\hline $\mathrm{M}$ & 2 & 2 \\
\hline $\mathrm{N}$ & 0 & -1 \\
\hline $\mathrm{O}$ & 3 & 3 \\
\hline $\mathrm{P}$ & -1 & 2 \\
\hline
\end{tabular}

In words, money invested in one unit of Option $\mathrm{M}$, for example, will be worth twice the amount you invest if Outcome 1 is observed $(2 * 150=300)$, but nothing if option 2 is observed $(0 * 150=0)$. If you invested $\$ 600$ in Investment Option M, representing four units, and Outcome 1 is observed, your investment will be worth $\$ 1,200$. However, if Outcome 2 is observed, your investment will be worth $\$ 0$.

To convert your earnings into dollars, we will multiply by 0.005 . Thus, 200 experimental dollars in total would be equal to $\$ 1.00$ in earnings that you take home with you today. The outcome that occurs will be determined by tossing a coin: a toss of heads yields Outcome 1 and a toss of tails yields Outcome 2. The same outcome applies to all four investment options. In other words, a coin will be tossed once.

[New Page] Practice Investment Decisions

Before you make your investment decision we will complete two practice rounds. First allocate your $\$ 3,000$ experimental dollars to the four investment options and cash. The sum must equal $\$ 3,000$. We will then flip a coin to determine the observed Outcome ( 1 or 2 ) and you can compute your ending portfolio value. 


\section{PORTFOLIO INVESTMENT SHEET}

Suppose the coin flip is heads so Outcome 1 is observed.

\begin{tabular}{|c|c|c|c|}
\hline Investment Option & Amount Invested & Payoff Factor & Ending Value \\
\hline $\mathrm{M}$ & & 0 & \\
\hline $\mathrm{N}$ & & -1 & \\
\hline $\mathrm{O}$ & & 3 & \\
\hline $\mathrm{P}$ & & $\mathbf{1}$ & \\
\hline Cash (dollars) & & - & \\
\hline Portfolio Value & & & \\
\hline
\end{tabular}

Your earnings are $0.005^{*}($ Ending Portfolio Value $)=\$$

\section{PORTFOLIO INVESTMENT SHEET}

Now, instead, suppose the coin flip is tails so Outcome 2 is observed.

\begin{tabular}{|c|c|c|c|}
\hline Investment Option & Amount Invested & Payoff Factor & Ending Value \\
\hline $\mathrm{M}$ & & 0 & \\
\hline $\mathrm{N}$ & & -1 & \\
\hline $\mathrm{O}$ & & 3 & \\
\hline $\mathrm{P}$ & & $\mathbf{1}$ & \\
\hline Cash (dollars) & & - & \\
\hline Portfolio Value & & & \\
\hline
\end{tabular}

Your earnings are $0.005 *($ Ending Portfolio Value $)=\$$

\section{[New Page] PORTFOLIO INVESTMENT SHEET}

Please allocate your $\$ 3,000$ experimental dollars to the four investment options and cash. The sum must equal $\$ 3,000$. We will then flip a coin to determine the observed Outcome ( 1 or 2 ) and you can compute your ending portfolio value.

\begin{tabular}{|c|c|c|c|}
\hline Investment Option & Amount Invested (\$) & Observed Payoff Factor (Outcome 1 or 2?) & $\begin{array}{l}\text { Ending Value (Amount Invested } * \text { Observed Payoff } \\
\qquad \text { Factor) }\end{array}$ \\
\hline \multicolumn{4}{|l|}{ M } \\
\hline \multicolumn{4}{|l|}{$\mathrm{N}$} \\
\hline \multicolumn{4}{|l|}{$\mathrm{O}$} \\
\hline \multicolumn{4}{|l|}{ Cash (dollars) } \\
\hline Portfolio Value & $\$ 3,000$ & - & \\
\hline
\end{tabular}

Your earnings are $0.005^{*}($ Ending Portfolio Value $)=\$$

[New Page] Cumulative Record Sheet

\begin{tabular}{|c|c|}
\hline Add $\$ 5$ for completion of the Survey & $\$$ \\
\hline Total amount earned for the Portfolio Investment Task & $\$$ \\
\hline Add $\$ 5$ for completion of Post-Experiment Questionnaire. & $\$$ \\
\hline Your total cash earnings for participation in this session. & $\$$ \\
\hline
\end{tabular}

[New Page] Questionnaire 
This final questionnaire is designed to collect general information. Such information may help us better understand differences found between participants in this study. Your answers are important for our research and you will be paid $\$ 5$ today for completion of the survey.

1. What university program are you in (MBA, undergrad, etc.)?

2. What year are you in the program (1st, 2nd, 3rd, or 4th)?

3. What is your major or concentration (e.g., finance, economics, etc.)?

4. What is your sex? male

5. What is your age?__ Years female

6. How tall are you? ___ feet and ___ inches

7. Relative to your friends, would you say your current financial position is above or below average? (circle the appropriate number)

\begin{tabular}{|c|c|c|}
\hline Weak & & Strong \\
\hline Financial & & Financial \\
\hline Position & Average & Position \\
\hline
\end{tabular}

8. How many years of professional work experience do you have?

9. How many finance and economics courses have you successfully completed at the university level? courses

10. How many finance and economics courses are you currently enrolled in? courses

11. How interesting did you find this experiment? (circle the appropriate number)

\begin{tabular}{|c|c|c|}
\hline Not very & & Very \\
\hline Interesting & Average & Interesting \\
\hline
\end{tabular}

12. For the time spent, how would you characterize the amount of money that you earned for participating in this experiment? (circle the appropriate number)

Nominal

Considerable

Amount Average

Amount

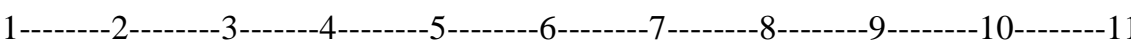

13. How would you characterize your financial expertise? (circle the appropriate number)

\begin{tabular}{|c|c|c|}
\hline Very Little & & Very \\
\hline Knowledge & Average & Knowledgeable \\
\hline
\end{tabular}

14. Have you ever traded securities for yourself or others? Yes no If yes, please describe.

15. A bat and a ball cost $\$ 1.10$ in total. The bat costs $\$ 1.00$ more than the ball. How much does the ball cost? cents

16. If it takes 5 machines 5 minutes to make 5 widgets, how long would it take 100 machines to make 100 widgets? minutes

17. In a lake, there is a patch of lily pads. Every day, the patch doubles in size. If it takes 48 days for the patch to cover the entire lake, how long would it take for the patch to cover half of the lake? days 